\title{
Photography against the Olympic Spectacle
}

\section{Introduction}

One of the most striking aspects of the transformation of the Lower Lee Valley prompted by the London 2012 Games was the erection in 2007 of an 11-mile long, 10-feet high blue fence around the perimeter of the future Olympic Park. Officially a health and safety device aimed at securing the demolition/construction site, it brought with it intense policing and surveillance as well as restrictions on public activities 'for security reasons' - including taking pictures (Beckett 2007). That image-making was considered such a threat as to lead the Olympic Delivery Authority (ODA) to prohibit it around the perimeter of the site may be regarded as excessive, or simply unconstitutional, but it should hardly come as a surprise. The 'success' of the Games relies on the capacity of the host city/country to afford 'adequate protection' to the Olympic brand and its sponsors - including the suppression of dissent (Boykoff 2011; Lenskyj 2008; Shaw 2008). To this end, the creation of an 'Olympic state of exception', characterised legally by the suspension of the ordinary juridical order on the grounds of 'necessity', and materially by the deployment of military-grade security strategies, has become a defining feature of the Olympic mega-event (Agamben 2005; Marrero-Guillamón 2011; Fussey et al. 2011).

In this article I will contrast the ODA's visual policy with the independent work of two photographers, Alessandra Chilá and Chris Dorley-Brown. The first section critically analyses the ODA's imagery, specially its use of computer-generated images (CGI). I will argue that these images, because of their purely constructed nature, are particularly good at revealing a political imagination at work. It would have been possible, but less interesting, to confront these 'fictional' images with 'real' documentary images of the area. I have chosen the work of Chilá and Dorley-Brown precisely because I wanted to avoid this crude dualism. Although still documentary photographers in essence, their work relies on extensive post-production rather than 
simple truth claims; their realism is (re)constructed. Their images raise important questions regarding the status of the documentary image, while also offering a counter-representation of the impact of the Olympics in East London.

\section{The production of consensus: the official imagery of the London 2012 Games}

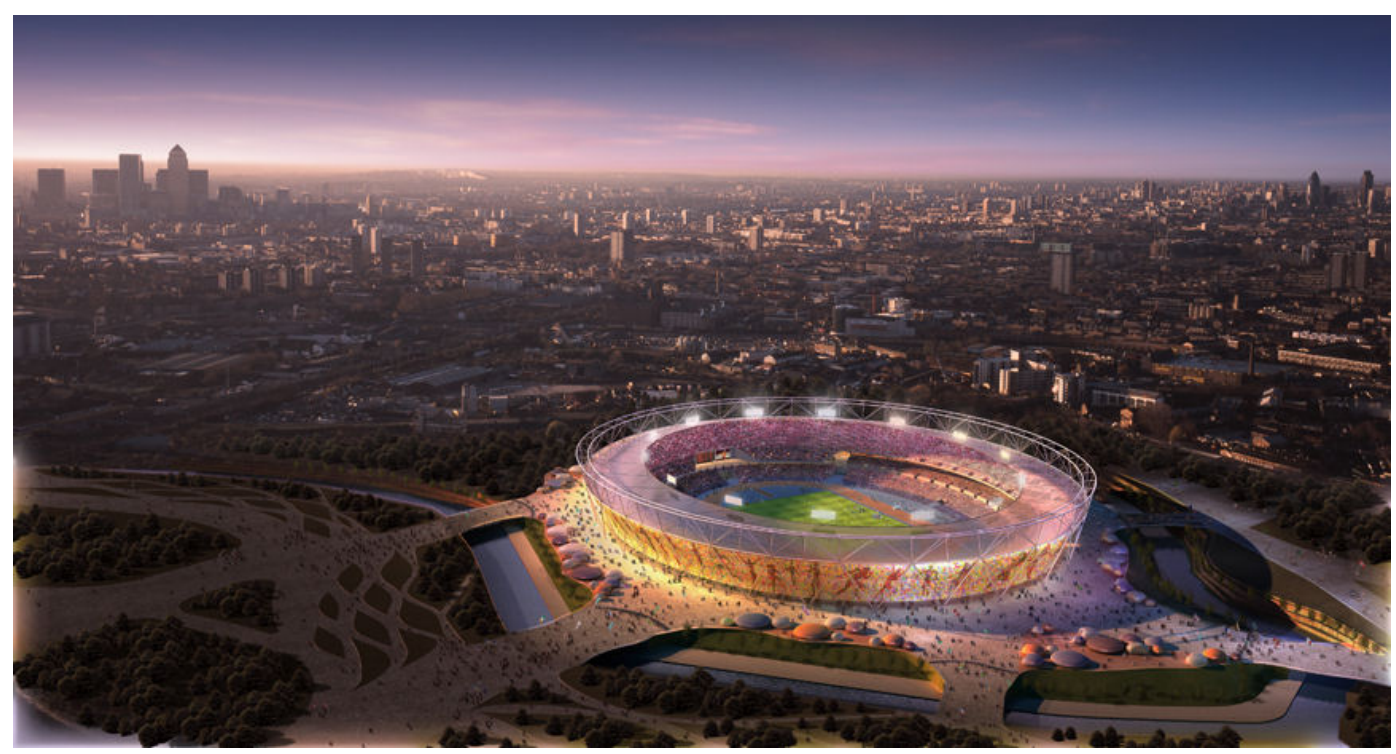

Figure 1. Olympic Stadium. Source: ODA

One of the ODA's most widely distributed images (Fig. 1) presents the preferred view of the Olympic Stadium, an aerial south-facing perspective in which the City and Canary Wharf occupy the edges of the horizon. The rest of the city, essentially nondescript, remains within this triangle of financial capitalism, urban renewal, and more financial capitalism. The soft sunlight comes from the East, suggesting an early morning; the stadium, however, is lit, full of spectators and surrounded by thousands of tiny figures on the bridges leading to it. The grandeur of the aerial perspective, the dissolution of citizenship into spectral forms, and the insistence on a visual connection between the stadium and Canary Wharf are all prevalent elements in the vision of the 
transformation sanctioned by the ODA. The celebration of built structures in and of themselves, accompanied by expressions of collective ecstasy, is certainly characteristic of many of the official images produced for London 2012. Construction achievements and communal stupor form, together with sporting events, the vast majority of the visual content made available by the organisers ${ }^{1}$. CGI have been an integral part of the public image strategy since the beginning, and have featured prominently in their communications. After most of the Olympic buildings were finished in mid 2011, aerial pictures joined them as the main vehicles for the dissemination of the official vision. In their own words: 'These computer-generated and aerial images illustrate the excitement and ambition of the London 2012 Olympic Games and Paralympic Games, and how the Olympic Park and venues might look' (ODA 2011).

The production and distribution of virtual images is a major component within processes of urban renewal. As Houdart has argued, they 'constitute an important and delicate part of the architectural argumentation as they offer a point of view into the future building, orientate and direct the attention and "subjectivise" the project' (Houdart 2008, 50). The function of these images is not exactly to reproduce a future built structure, but to anticipate its relation to its context: 'Renderings provide an idealized scenario capable of suggesting possible uses and ways of life related to the activities and functions conceived in the project' (Sonda 2011, 287). They play a key role in visualising the impact of transformation and in defining the scope and terms of the debate. Far from being mere technical architectural images, they perform the very political task of virtually assembling the future world (Söderström 2011). Devoid of the 'indexical obligation' of traditional photography, CGI are pure exercises of political imagination. Approaching them as such can shed light on the 'representations of space' (and society), i.e. the ideological nature of the conceptualised space of planners, urbanists, managers, etc. (Lefebvre 1991). 


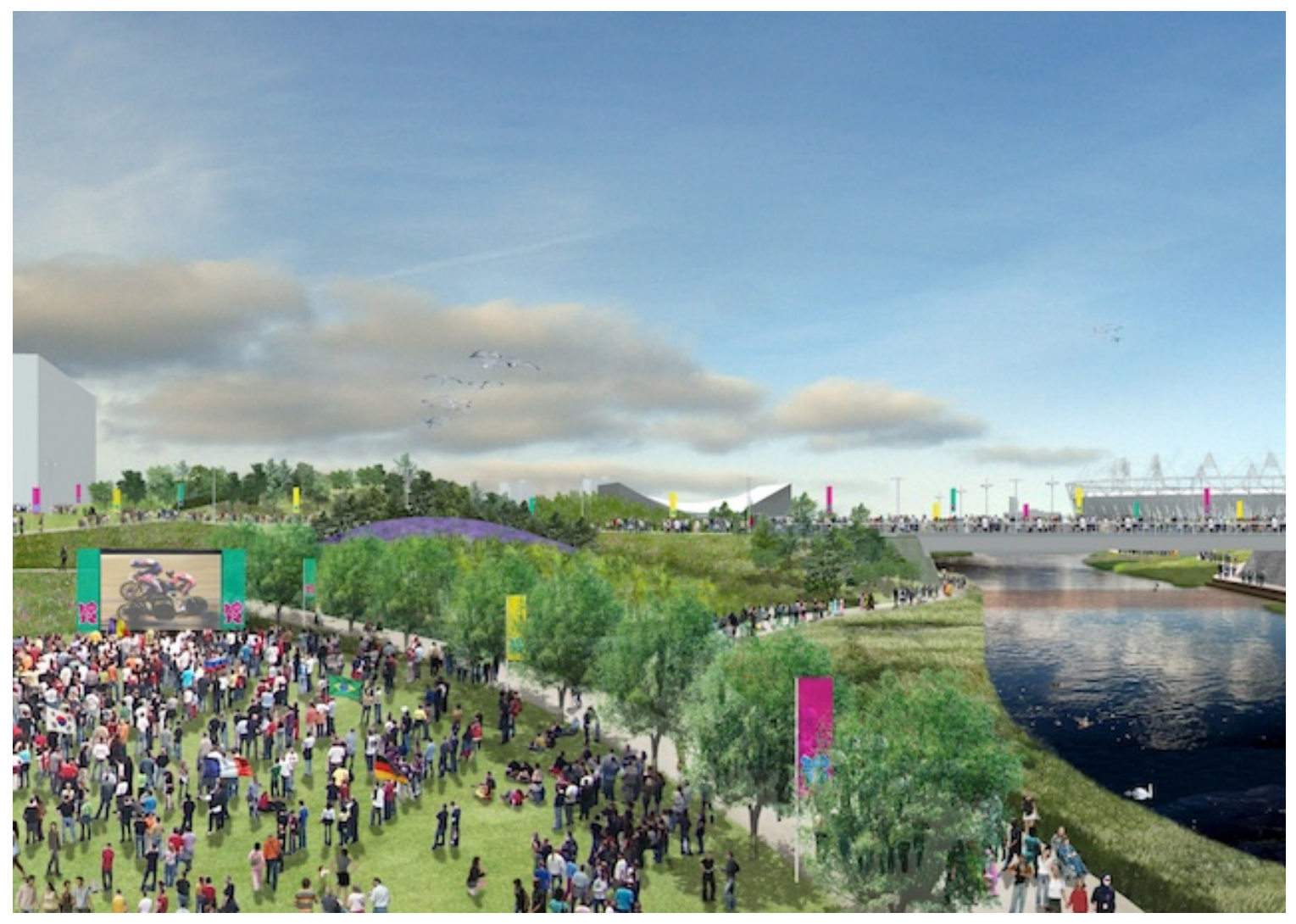

Figure 2. Games branding no. 9 'cycling'. Source: ODA.

Figure 2 is a good example of this. The scene is constructed from an elevated, panoramic viewpoint in which the relationship between the elements takes precedence over the elements themselves. The Olympic event, presumably happening in the distant venues and broadcast through a screen, provides the canvass for a perfect communion between nature and society. The Lower Lee Valley has been transformed into an exuberant natural landscape filled with trees, swans and birds, as well as a spotless public space for the collective enjoyment of the Olympics. A variety of national flags and skin colours are here used to signify 'diversity', while their very coexistence arguably signifies 'harmony'. The community of ticket holders represents the victory of consensus. The absent elements are equally significant in the configuration of this vision: there are no shops, no rubbish or rubbish bins, nobody drinks or eats, everyone behaves nicely. Remarkably, there is no security either: no CCTV cameras, not a trace of the electric fence that 
surrounds the park, no policemen or security guards. The complete disappearance of the city, its social dynamics and its history is here simply achieved through a series of omissions. In this regard, it is worth going back to the comparative sophistication of Figure 1, where the effect is produced by a lighting trick: while the stadium is powerfully lit, the city is kept in the dark, silent, under control.

The importance of the 'virtual' in the configuration of a seamlessly consensual image of the radical reshaping of the Lower Lee Valley, I will argue, should be understood in relation to the aforementioned prohibition of taking images in and around the Olympic Park. Although the 'blackout', as I will call it, was not successful in preventing the production of unsanctioned images entirely, it effectively criminalised the act of taking pictures and subjected photographers and filmmakers to the discretion of police officers and private security guards. Leaving aside the (il)legality of this measure, it is important to note how the 'blackout' and the 'virtual' reinforce each other: the former produces an 'empty' space, a visual black hole which allows the latter to operate almost in isolation, without competition, untouched and unchallenged by competing representations.

\section{Shedding shadows on the Olympic spectacle}

In spite of the restrictions discussed above, critical images have indeed been produced. To name a few, Anja Kirschner and David Panos' spaghetti western Trail of the Spider (2008) explores issues of land grabbing in East London through the language of the Wild West; Hilary Powell's short film The Games (2008) stages a surreal Olympic competition amongst ruins and places set to disappear; photographer Giles Price (E20 12 Under Construction, 2011-ongoing) circumvented the prohibition of taking images of the site by hiring a helicopter periodically and 
documenting the colossal transformation of the area from the air; Geshe Würfel's Go for Gold (2006-ongoing) began surveying this landscape before the transformation started, dragging a sense of memory and loss into the present; photojournalists such as Mimi Mollica and Martin Slavin have documented the displacement of communities in the area.

Without attempting to be in any way exhaustive, one could argue that critical images have mostly been concerned with 1) excavating the secret and rich history of the area vs. the official discourse of the 'wastelands'; and 2) exposing the violence of the transformation on its social and environmental fabric. Most of these projects have done so through clearly defined either 'factual' or 'fictional' strategies. In this article, I have chosen to concentrate instead on two projects that ignore this distinction. By engaging with documentary work which is openly constructed I hope to reclaim a concept of realism which is not tied to notions of transparent access, but that does not give up the commitment to represent a 'real world out there' either. John Roberts has similarly defended the use of the term, as a way out of deconstructionist, poststructuralism critiques of documentary practices as positivist endeavours:

For realists the critical understanding of, and critical intervention in, reality is a necessary - and inevitable - part of this process. Realism, essentially, is a fallibilistic account of a transitive, stratified and differentiated world; it is not a window on a homogeneous and present or phenomenal reality. Consequently, claims to the realist content of representations are not governed by the reflection of their objects... there is no such thing as the realism of a photograph... The 'realist-effects' and cognitive and aesthetic merits of such photographs will always be context-determined. (Roberts 1998, 5-6)

Roberts is interested in the development of a 'dialectical realism' based on 'the study and criticism of its object as the exposure of contradictions' $(1998,6)$, from which I would like to retain the idea of photography as an essentially epistemological practice. Looking at photography as a knowledge-production activity makes it possible to situate the discussion on realism and 
transparency in relation to important epistemological debates in social sciences. The work of Donna Haraway (1991) and Bruno Latour (2005) around situated knowledge and the question of objectivity is here particularly relevant. Very briefly, through the study of laboratory science, these authors found that 'fabrication and artificiality are not the opposite of truth and objectivity', and that in fact 'no laboratory scientist was ever confronted with an object "out there" independently of the work to "make it visible" (Latour 2005, 124, 240). This is a point that Roberts raised in relation to Jeff Wall's work:

In essence, what the new imaging techniques produce is not the death of the 'truth' of the photograph, but the cultural displacement of the indexicality of the photograph as an automatic truth-effect. The easily manipulable image, then, relieves the photograph of the burden of veracity, leaving the image open to a recognition of the relationship between the 'real' and its discursive construction. In consequence, the image will become a more direct focus of struggle over the political demands of interpretations. (Roberts 1998, 221)

Paraphrasing Latour, we can conclude that the realism defended here is both artificial and accurate - indeed all the more accurate because it is artificial.

\section{Decisive Moments}

Chris Dorley-Brown's series Decisive Moments presents daily scenes in the Hackney Wick/Fish Island area, related in different ways to the advent of the Olympics on the other side of the canal. These are hardly Cartier-Bressonian moments, though, as most of them are composite pictures. Rather than 'prowling the street' waiting for the decisive moment to happen, ready to 'pounce' and 'trap' it (as Cartier-Bresson famously explained his method), DorleyBrown assembles the decisive moments by layering multiple exposures on a single frame and organising its elements in a narrative way. 
I will focus my analysis on two images: Early Shift Arriving and Roach Road. The two pictures are based around a common structure: they are taken from Hackney Wick and Fish Island looking East towards the Olympic Park, whose presence is established through a distant 'iconic' element (the blue fence and the Olympic stadium, respectively). The two pictures were also produced following the same method: a location and framing was chosen by the photographer, multiple exposures were taken from the same position, and a single image was then assembled during post-production. No elements were imported from other situations, the final image being a montage of the raw, unstaged material gathered in the field. The cinematographic vocabulary is appropriate to describe both the procedure and the results. Dorley-Brown's images involve the editing of events on a timeline, only that the latter is compressed into one frame. I will call this approach the 'layering of time onto space', and its significance lies in its capacity to reveal spatial conflicts through the juxtaposition of different temporalities. The result is reminiscent of Jeff Wall's tableaux pictures, with the key difference that whereas the latter were inscribed in a dialogue with art history, the main impulse in DorleyBrown's is outward-looking, to document an actual external reality (their modes of exhibition and distribution are very different too, and are discussed below).

In Early Shift Arriving (Fig. 3), the blue fence delimiting the construction site occupies the foggy horizon of the image. Its 'Welcome to the Olympic Park' sign is offset by the early morning mist and another sign, this one much nearer and more clearly visible, that warns drivers of a 'Weak Bridge' ahead. The road, however, is closed to the traffic. The sidewalks and the pavement are instead taken by people walking away from the camera and towards the fence. Workers, one can assume considering the title of the image, although they are all walking on their own, are dressed in different ways and seem to be of different ages. More than a homogenous collective they are an aggregation of anonymous individuals going to work. We 
cannot see their faces, only their backs and their heavy, slightly zombie way of walking. This mysterious labour force that is finding its way into the Olympic machine is framed by large warehouses, once industrial buildings and now converted into artists' studios. Looking at the Olympic site from Hackney Wick there is no spell: the prospect of both workers and build structures is uncertain, and the seduction of the Games is muted by the foggy atmosphere.

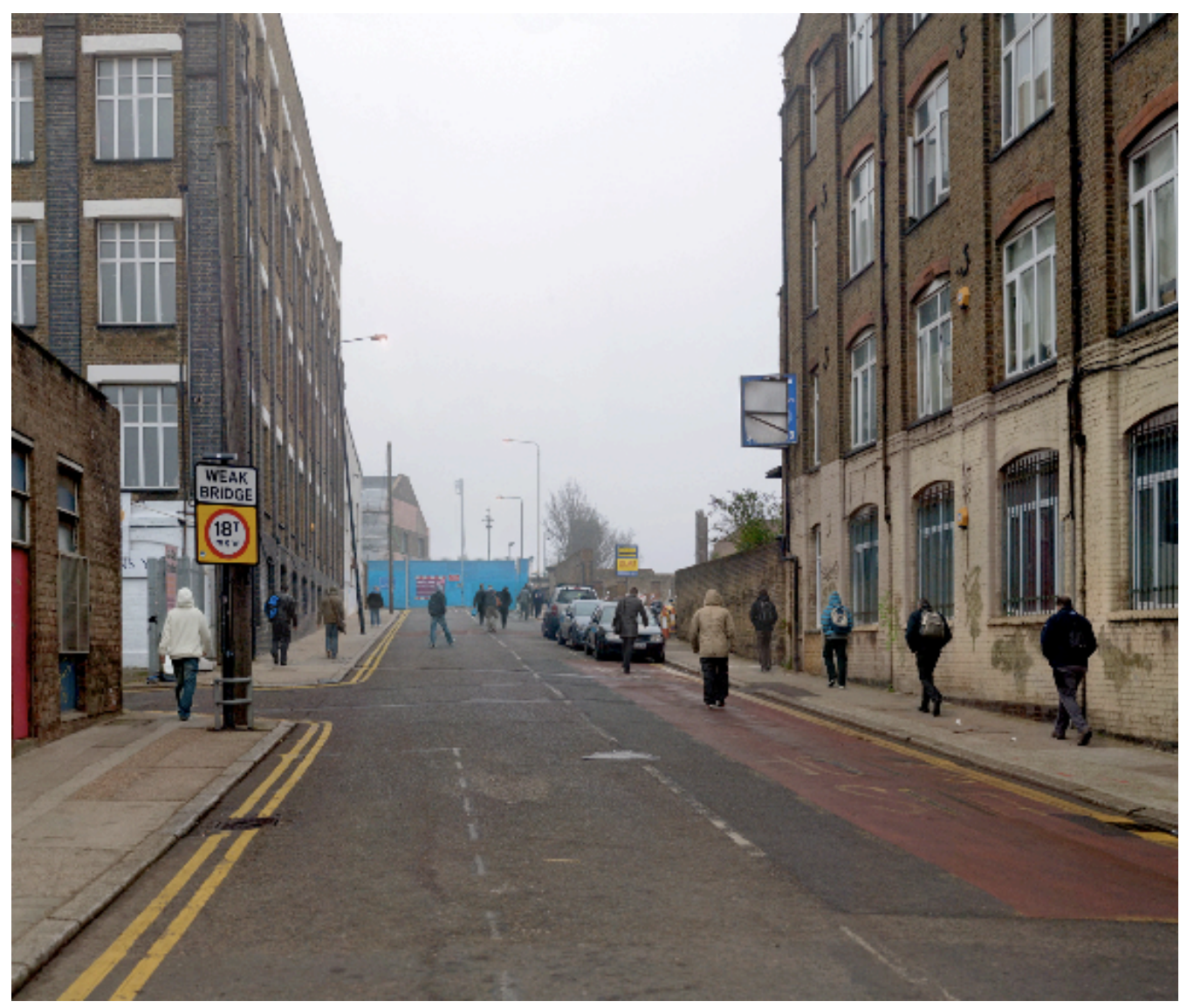

Figure 3. Chris Dorley-Brown, Early Shift Arriving, 2011. Courtesy of the author.

Roach Road shows an urban/industrial street corner, dominated by the presence of the Olympic Stadium in the distance. The scene takes place on a warm late winter morning, one can guess taking into consideration the light, the leafless trees and the clothes people are wearing. An independent cafe (Counter Café) with people sitting outside occupies the left part of the picture; a young man pushing his 'fixie' bike is crossing the street; and two men talk on the sidewalk on 
the right of the frame. Various cars are parked; among them, a small transport van, a Mercedes convertible and a Volvo. There are three other people further away, walking or cycling. A warehouse with a closed shutter and a sign that reads 'Stour Space' (an art gallery and multi-use space) stands at the end of the road.

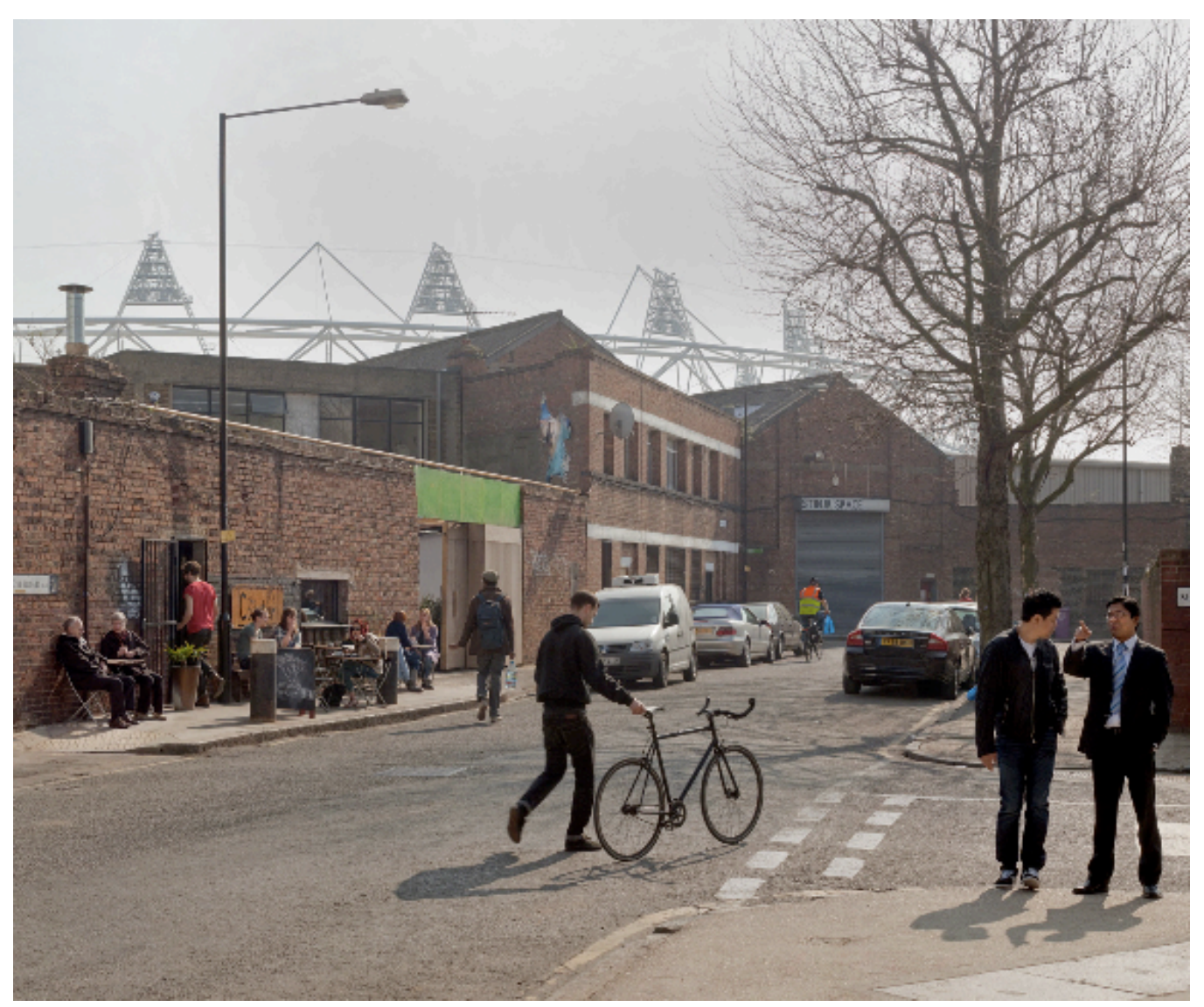

Figure 4. Chris Dorley-Brown, Roach Road, 2011. Courtesy of the author.

Through a clever use of time on space, the picture constructs a convergence between a series of dynamics operating in the area. The arrival of the Olympics is juxtaposed to the (still) informal colonisation of the area by artists, 'hipsters', and even 'yuppies'. The image raises the question of the relationship between them, perhaps the tension among them, but does not resolve it. Rather, it suspends it. The relaxed scene at the cafe, where people are enjoying caffeine, sun 
and conversation, is in contrast with the seriousness of the man in a suit. His pointing gesture, examined by the younger man next to him, seems to be a warning (of what we cannot be sure: the interest of the City workers, maybe?). Simply by moving the Olympic icon to the background, Dorley-Brown puts it in relation to the complexity of the local context. The lightness of the CGI promises is bracketed here by the density of these many other stories never told. In fact, Decisive Moments was produced as part of The Cut, a project by [ $\mathrm{s} \mathrm{p} \mathrm{a} \mathrm{c} \mathrm{e} \mathrm{]} \mathrm{which}$ combined photography, oral history, drawings, archival work and community art in an investigation of the 'Hackney Cut', as the area is also known. In addition to an exhibition in summer 2011 and a web presence, the project was disseminated through a free newspaper, in which Dorley-Brown's pictures were printed.

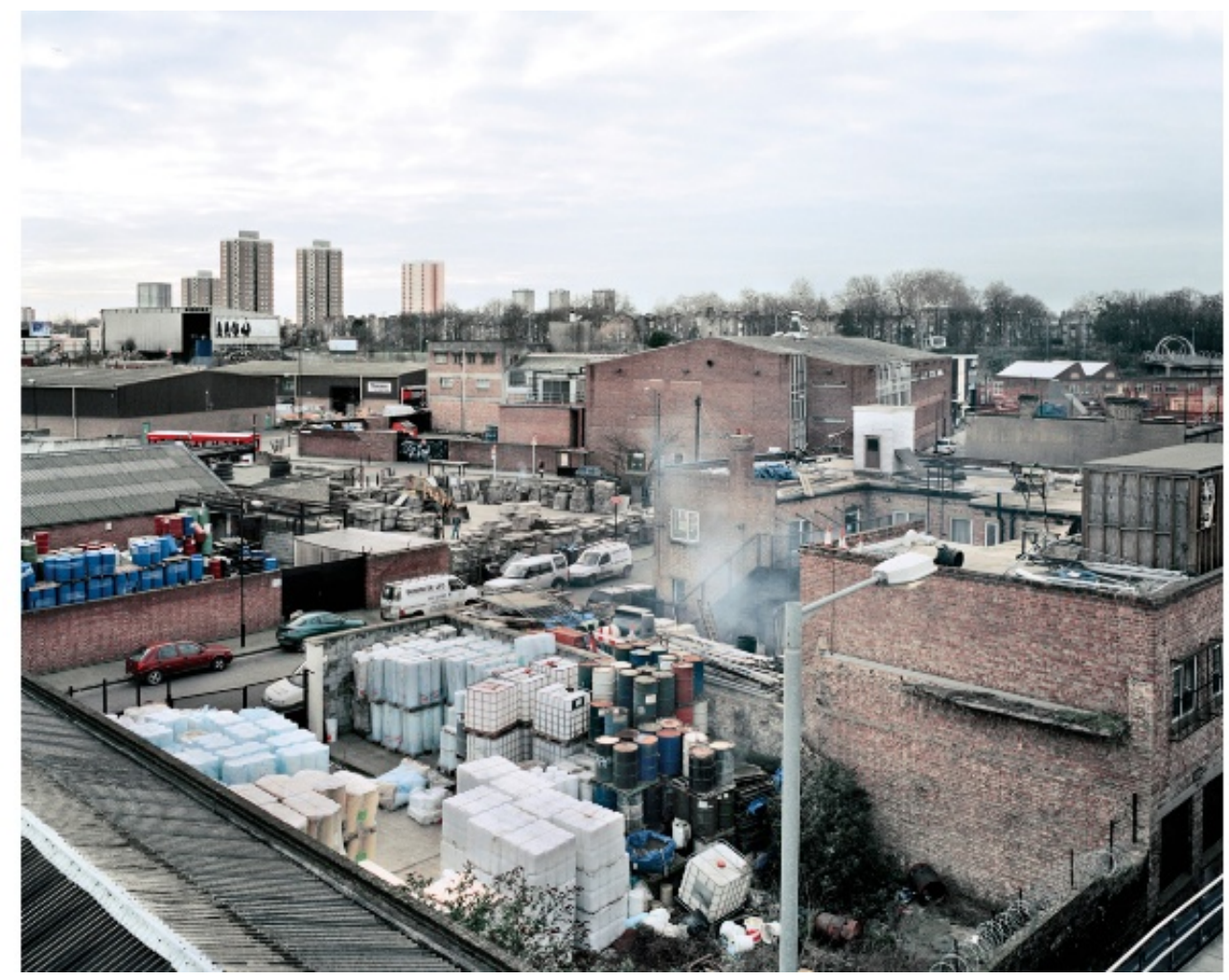

Figure 5. Alessandra Chilá, Hackney Wick, 2007. Courtesy of the author. 


\section{Olympian Visions}

Alessandra Chilá's Olympian Visions engages as a whole with the so-called 'wastelands' of the Lee Valley, and finds in them a subterranean, perhaps even subaltern, stream of life. Car garages and mechanics, amateur motocross riders, allotments, informal settlements, or indigenous vegetation all find a home in a project that surveyed these silenced landscapes at a moment (in early 2007) when the Olympic transformation was about to materialise. The project is not ${ }_{2}$ however, about anticipating or lamenting a loss, but about excavating and reconstructing a social narrative in connection to the secret life of the area.

I will focus my attention on two pictures: Hackney Wick and Lee Valley. The first (Fig. 5) presents an elevated view of Hackney Wick, looking Southwest from its train (now Overground) station. Various tower blocks lie in the horizon, while the rest of the landscape is eminently industrial: yards, warehouses, barrels, pallets, delivery vans. The scene is populated by several events: a bus departing, somebody waiting for another bus, three men talking in a yard, a chimney emitting smoke. Lee Valley shows a group of eight people involved in picking up and burning dry weeds in the marshes. There is a fair amount of smoke, and an important section of the plot has already been cleared. This vaguely rural scene is ${ }_{2}$ however, surrounded by industrial buildings, a tower block in the distance, and high-voltage electricity lines in the top right corner of the image.

Like Dorley-Brown's, these photographs rely on a constructed realism. Post-production techniques were used to achieve the desired effect, be it multiple exposures in the case of Hackney Wick or the removal of elements in Lee Valley. Having abandoned the fetishism of the pure documentary image, Chilá synthesised and refined the original capture/s into conceptual 
and narrative images that responded to her understanding of the situation, rather than an indexical record of it. But there is another level at which they articulate the critique to transparency. These two images were first exhibited in art galleries as a diptych of large lightboxes (Fig. 6). The reference to Jeff Wall is unavoidable, with the lightbox format establishing a dialogue with advertising practices, especially relevant here, considering the 'spectacularisation' of the transformation promoted by the ODA. As well as allowing the viewer to scrutinise the enormous amount of detail in these pictures, the lightboxes fully embraced the seduction of billboards as a mode of address. This could be interpreted as an attempt to confront the official images of change in their own territory, although the very fact that they remained hung on a gallery wall within a context of art trading limited ${ }_{2}$ in my opinion ${ }_{2}$ the power of the gesture.

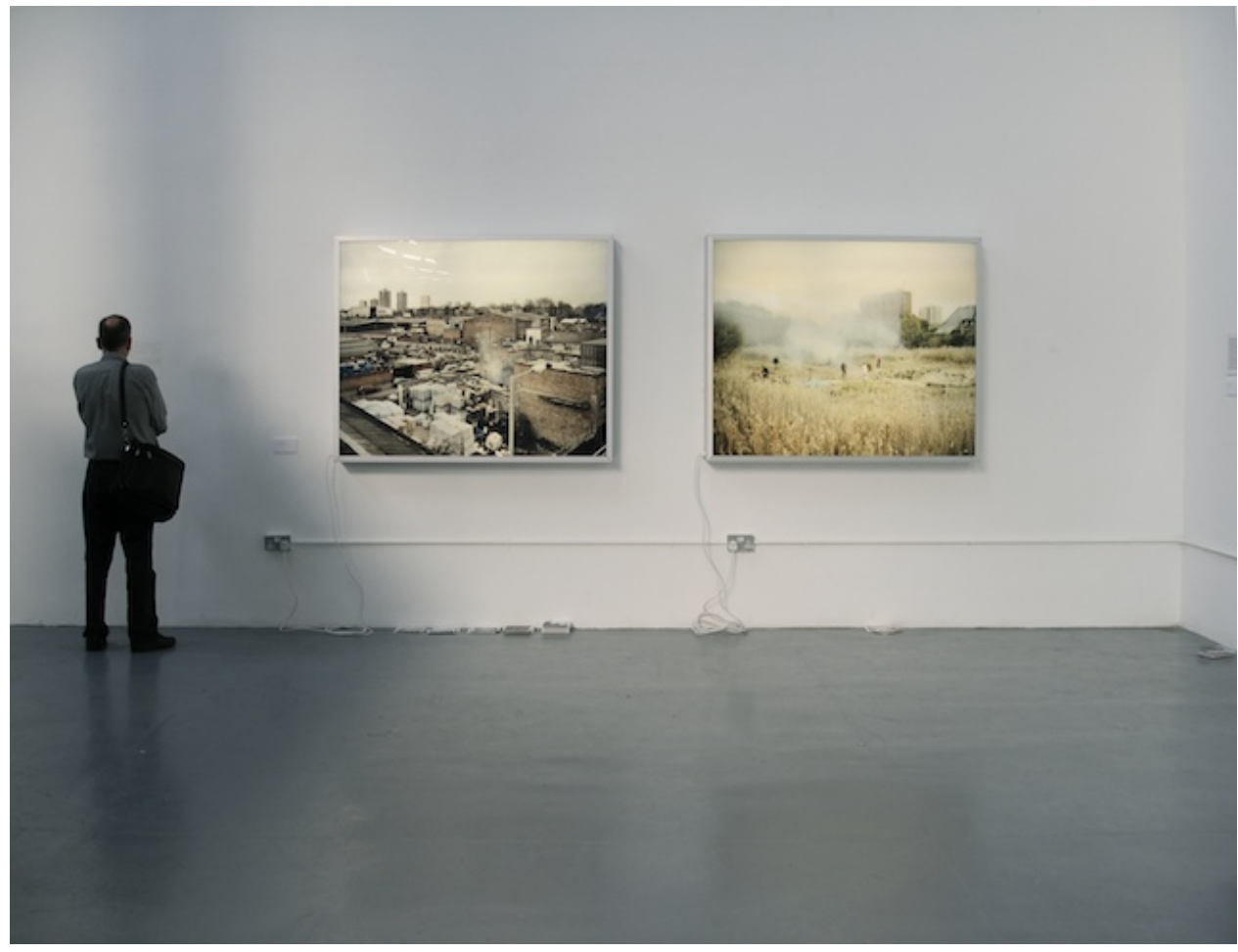

Figure 6. Alessandra Chilá, Installation Shot. Courtesy of the Author 
Aware of the commodification of her own work produced by the interaction between the gallery space and the lightboxes — and their prohibitive cost_- Chilá subsequently radically reformulated the distribution of the images. They became humble $10 \times 15 \mathrm{~cm}$ postcards ${ }_{2}$ which combined a photograph on the front with a text on the back. In the case of Lee Valley (Fig. 7), the text read:

400 acres of common land will be swallowed up in the construction of the Olympic park. The historical commons of Hackney were given to the people of London in 1894 for their enjoyment and recreation 'in perpetuity'.

'O yea $\mathrm{O}$ yea $\mathrm{O}$ yea they are taking our land away'

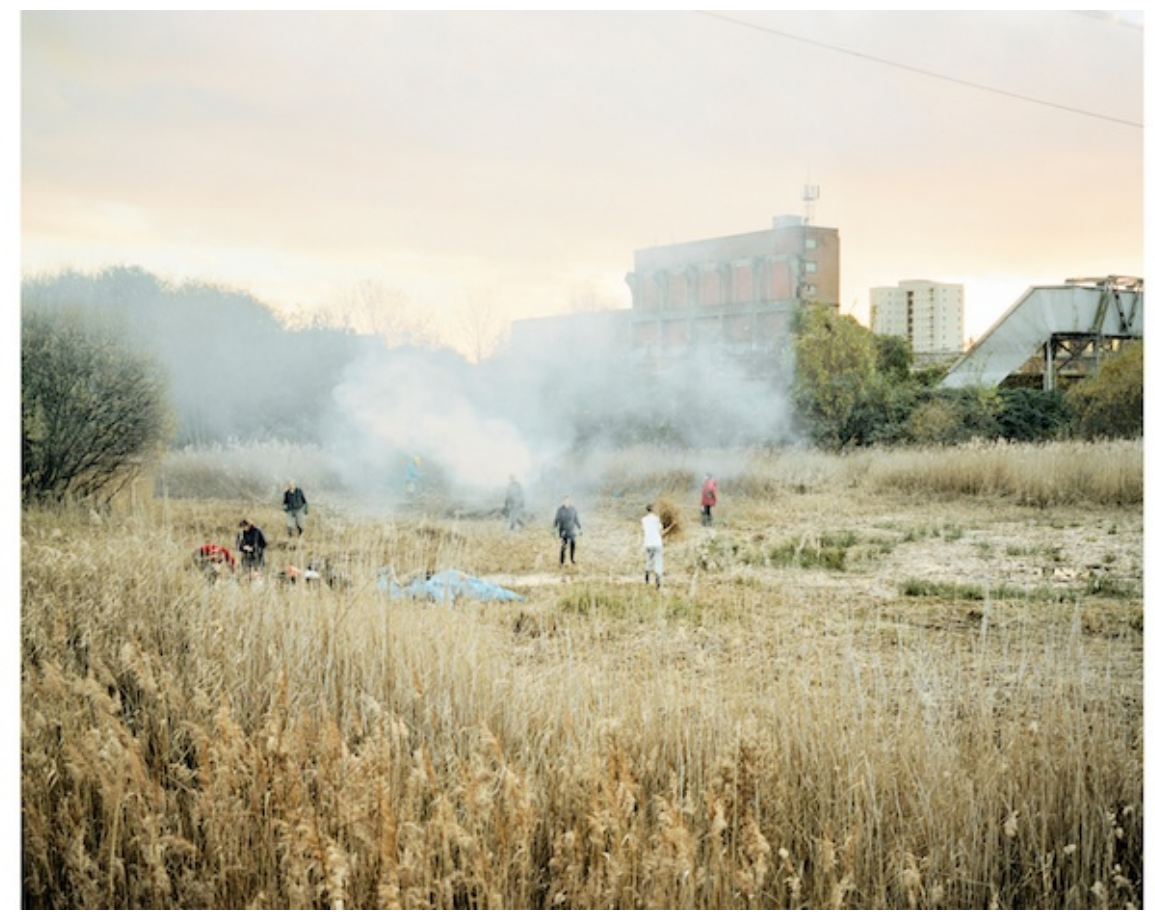

Figure 7. Alessandra Chilá, Lee Valley, 2007. Courtesy of the author.

The function of the text was here crucial in introducing a critical discourse with the transformation of the area not explicitly present in the images themselves. The incontestable beauty of the images was in this way counterbalanced by the crude militancy of the text. As in 
Martha Rossler's classic The Bowery in Two Inadequate Descriptive Systems, the disjunction between the image and the text served as a commentary on the partiality of both, as well as their uneasy collaboration. The so-called transparency of the documentary image is short-circuited by the text. As Allan Sekula (1984) argued some time ago, this type of image-text production presents an antagonism to the formalist closure of late modernism. Whereas Chilá's images seem to create a self-contained universe (albeit an opaque one), the text points towards forces and dynamics outside of them. Also, the images, in their new incarnation as postcards, abandoned the gallery for the public realm, their accessibility and circulation made possible by the cheap distribution method and its intended use as a mailing device. As postcards, these images now had the ability to take these spaces of conflict to unforeseeable places.

\section{Conclusion}

The London Olympics' visual identity has been determined in key ways by the ODA's visual policy. The imposition of a 'blackout' in the area, diligently enforced by the police, was complemented by an intensive production of official imagery. Within this context, the virtual worlds constructed with CGI played an important role in disseminating the sanctioned vision for the future of the Lower Lee Valley. I have tried to show how understanding these images as acts of political imagination can be productive, especially in relation to the production of images of consensus.

The unconditional celebration of the transformation inscribed in the official images and perfectly encapsulated by the ODA's own motto, 'Demolish, dig, design'- has however been contested. The second part of this article presented and discussed two photographic projects that cast a shadow on the alleged prospects for the area. The work of Alessandra Chila and Chris 
Dorley-Brown articulates a counter-narrative of these changes, and does so through a productive debate around the status of documentary images. Their response has not relied on a recalcitrant affirmation of naturalistic photography, but on an open engagement with the possibilities of image manipulation. These are pictures that move away from 'the poetic epiphanies of the decisive moment' (Campany 2007: 13) typical of classic documentary photography to focus on the production of artefacts with the capacity to incorporate conflict, history and memory.

In a context in which the Olympic authorities have a tremendous capacity to propagate their visual representations (and political imagination), it is a brave and committed gesture on the part of these photographers to have searched for ways of distributing their work outside the traditional venues (i.e. a newspaper, postcards). Whilst the official images only managed to turn their back on the city and its history, Chilá and Dorley-Brown have done the opposite and found in it an ally in the struggle for a more just representation of the transformation of East London. 


\section{References}

Agamben, Giorgio. 2005. State of exception. Chicago: University of Chicago Press, January 15.

Beckett, Andy. 2007. "Cordon blue." The Guardian, September 21. http://www.guardian.co.uk/society/2007/sep/21/communities.

Boykoff, Jules. 2011. "The anti-Olympics." New Left Review (67): 41-59.

Campany, David, ed. 2007. The cinematic. London: Whitechapel.

Fussey, Pete, Jon Coaffee, Gary Armstrong, and Dick Hobbs. 2011. Securing and Sustaining the Olympic City: Reconfiguring London for 2012 and Beyond. Farnham and Burlington: Ashgate Publishing.

Haraway, Donna J. 1991. Simians, cyborgs, and women: the re-invention of nature. London: Free Association.

Houdart, Sophie. 2008. "Copying, Cutting and Pasting Social Spheres : Computer Designers " Participation in Architectural Projects." Science Studies 21 (1): 47-63.

Latour, Bruno, and Peter Weibel. 2005. Making things public: atmospheres of democracy. Karlsruhe / Cambridge, MA: MIT Press / ZKM.

Lefèbvre, Henri. 1991. The production of space. Oxford: Wiley-Blackwell.

Lenskyj, Helen. 2008. Olympic industry resistance: challenging Olympic power and propaganda. New York: SUNY Press.

Marrero-Guillamón, Isaac. 2011. "London 2012: espacio de excepción." urbe. Revista Brasileira de Gestão Urbana (Brazilian Journal of Urban Management), 3(2), 177-188.

Olympic Delivery Authority (ODA). Image library, London 2012. Webpage: http://www.london2012.com/press/image-library/. Accessed: Nov 30 2011.

Roberts, John. 1998. The art of interruption: realism, photography, and the everyday. Manchester; New York: Manchester Universtiy Press.

Sekula, Allan. 1984. Photography against the grain: essays and photo works, 1973-1983. Halifax, Canada: Press of the Nova Scotia College of Art and Design.

Shaw, Christopher A. 2008. Five ring circus: Myths and realities of the Olympic Games. Gabriola Island: New Society Publishers.

Söderström, Ola. 2011. "How Images Assemble the Urban World." New Geographies 4.

Sonda, G. 2011. Envisioning Cities. Paper presented at the MIC - My Ideal City Conference, Venice, 12-13 May.

${ }^{1}$ See http://www.london2012.com/press/image-library/ 